\title{
NEUROMUSCULAR ELECTRICAL STIMULATION OF MEDIUM AND LOW FREQUENCY ON THE QUADRICEPS FEMORIS
}

\author{
ESTIMULAÇÃO ELÉTRICA NEUROMUSCULAR DE MÉDIA E BAIXA \\ FREQUÊNCIA NO MÚSCULO QUADRÍCEPS FEMORAL
}

\author{
Carlos Eduardo Pinfildi ${ }^{1}$, Rodrigo antonio Carvalho Andraus ${ }^{2}$, Ligia Megumi lida ${ }^{2}$, Rodrigo Paschoal Prado 3 \\ 1. Universidade Federal de São Paulo (UNIFESP), Department of Movement Health and Science, Santos, SP, Brazil. \\ 2. Universidade Pitágoras Unopar (UNOPAR), Program stricto sensu in Rehabilitation Science, Londrina, PR, Brazil. \\ 3. Universidade Federal de Goiás (UFG), Department of Physical Therapy, Jatai, GO, Brazil.
}

\section{ABSTRACT}

Objective: The purpose of this study was to investigate the effects of neuromuscular electrical stimulation (NMES) in different frequencies on the quadriceps femoris. A randomized, controlled, blind cross-sectional study. Methods: Thirty subjects (12 men and 18 women), with an average age of 24.67 years, weight of $65.62 \mathrm{~kg}$ and height of $1.69 \mathrm{~m}$ were evaluated. Three random test conditions were applied: maximum voluntary isometric contraction (MVIC), maximum voluntary isometric contraction with medium frequency current (MVIC-MF) and maximum voluntary isometric contraction with low frequency current (MVIC-LF). Four MVICs were applied in each situation. The time between different isometric contraction types was 90 seconds while the time between the same conditions of contraction was 10 seconds. Results: Two-way ANOVA test showed that MVIC-MF had higher values for peak torque than MVIC-LF $(p=0.02)$. Significant statistical results were found when comparing MVIC-MF and MVIC ( $p=0.03)$, but not for MVIC and MVIC-LF $(p=0.52)$. Conclusion: Maximum voluntary isometric contraction associated with medium-frequency electrical stimulation was more effective than other NMES conditions. Level of Evidence II, Therapeutic Studies - Investigation of treatment results.

Keywords: Quadriceps Muscles. Transcutaneous electrical nerve stimulation. Isometric contraction. Torque.

\section{RESUMO}

Objetivo: A finalidade deste estudo foi investigar os efeitos da estimulação elétrica neuromuscular (EENM) em diferentes frequências sobre o músculo quadríceps femoral. Estudo randomizado, transversal, controlado e cego. Métodos: Foram avaliados trinta indivíduos de ambos os sexos (12 homens e 18 mulheres) com média de idade de 24,67 anos, peso $65,62 \mathrm{~kg}$ e altura 1,69 m. Os indivíduos foram submetidos a três condições de testes randomizados: contração voluntária isométrica máxima (CVIM), contração voluntária isométrica máxima associada à corrente de média frequência (CVIMMF) e contração voluntária isométrica máxima associada à baixa frequência (CVIMBF), sendo realizadas quatro repetições de CVIM em cada situação. O tempo entre as diferentes condições de contrações isométricas foi de 90 segundos e o tempo entre as contrações isométricas das mesmas condições foi de 10 segundos. Resultados: O teste ANOVA mostrou que a CVIMMF obteve valores de pico de torque maiores do que a CVIMBF ( $p=0,02)$, com diferença significativa. Foram encontrados resultados com significância estatística ao comparar CVIMMF e CVIM ( $p=0,03)$, mas não entre CVIM e CVIMBF ( $p=0,52)$. Conclusões: A contração voluntária isométrica máxima associada a EENM de média frequência foi mais efetiva do que as outras situações de EENM. Nível de evidência II, Estudos Terapêuticos - Investigação dos resultados do tratamento.

Descritores: Músculo quadríceps. Estimulação elétrica nervosa transcutânea. Contração isométrica. Torque.

Citation: Pinfildi CE, Andraus RAC, Lida LM, Prado PR. Neuromuscular electrical stimulation of medium and low frequency on the quadriceps femoris. Acta Ortop Bras. [online]. 2018;26(5):346-9. Available from URL: http://www.scielo.br/aob.

\section{INTRODUCTION}

Neuromuscular stimulators can produce electrical pulses, which can cause excitation of peripheral nerves and, consequently contraction of muscular tissue. Therewith, the use of electrical stimulation by physical therapists to increase or maintain muscle performance has gained popularity.

Some factors like well-being of patient, location of electrodes, frequency and current intensity, encouraged researchers to investigate medium and low frequency currents in an attempt to minimize the discomforting as a result of the use of neuromuscular electrical stimulation (NMES). ${ }^{1}$

Recruitment of motor units during voluntary contraction follows the principles of that the cell body size of motor neurons determines the order in which motor units are activated. Typically, type I (slow-twitch) fibers are recruited before the type II (fast-twitch) fibers according to the increasing in muscular contraction. Additionally, the order

All authors declare no potential conflict of interest related to this article.

Work conducted at the Cohen Orthopedic Institute, Rehabilitation and Sports Medicine - São Paulo - Brazil.

Correspondence: Rodrigo Antônio Carvalho Andraus. Center for Research in Health Sciences. Universidade Pitágoras Unopa (UNOPAR). Marselha, 591, Jd. Piza, Londrina, PR, Brazil.86041-140. rodrigoandraus@gmail.com 
of recruitment of type II fibers occurs in the following order: First type Ila fibers and after type Ilb fibers.

Studies involving electrical stimulation have suggested a selective recruitment and preferred the fast-twitch fibers (type II). This hypothesis, however, is based on the results of fatigue studies in humans, demonstrating limited scientific evidence.

The force of contraction produced by NMES has been reported, in some studies, as being higher than the maximum voluntary contraction. ${ }^{2}$ However; some studies report that use of NMES produces a significantly lower contraction force or equal force to the maximum voluntary contraction (MVC). Therefore, in untrained individuals can generate greater force than the MVC by electrical stimulation. ${ }^{3}$

The low-frequency electric current is that less than $1000 \mathrm{~Hz}$ and are generally used for muscle contraction below $100 \mathrm{~Hz}$. The stimulation frequency of $50 \mathrm{~Hz}$ is fast enough to cause muscular contraction even in motor units of rapidly contraction. Nevertheless, some studies using lower frequencies $(30-35 \mathrm{~Hz})$ achieved positive results. ${ }^{4}$

In other investigated the influence of NMES in producing muscular force using low-frequency current $(70 \mathrm{~Hz}, 250 \mu \mathrm{s}){ }^{5}$ The torque generated by the electrical current was $45.05 \%$ of the maximum voluntary contraction and superposition of electrical stimulation to the MVC showed no significant increase in the knee extensor torque in the individuals analyzed.

The medium-frequency alternating current is defined as current frequency between 1 and $10,000 \mathrm{~Hz}$. Interferential current $(4.000 \mathrm{~Hz})$ and Russian current $(2.500 \mathrm{~Hz})$ are the most popular NMES utilized. The reason to use higher frequency than $1000 \mathrm{~Hz}$ is that the skin works as a barrier to capacitive current flow. As the current frequency applied increases, the skin impedance decreases. ${ }^{6}$ Above $1.000 \mathrm{~Hz}$ skin impedance is low, less energy is dissipated to the surface of epidermis and a larger proportion of energy is intended to stimulate deeper tissues. ${ }^{7}$ Thus, it is expected that the devices provide medium frequency current $(1-10.000 \mathrm{~Hz})$ may be able to produce higher levels of muscle contraction with less discomfort than the low frequency stimulators.

It is important to considered well-being of patient during training with electrical stimulation because the discomfort is considered one of the limiting factors in the use of NMES in promoting increased muscle strength. ${ }^{8}$ An ideal electrical stimulator should be able to increase muscle strength with the least possible discomfort during stimulation. ${ }^{9}$ A Russian physiologist ${ }^{10}$ indicated that using frequency of $2.500 \mathrm{~Hz}$; he was able to increase the strength of the subjects by $30-40 \%$ in 20 stimulation sessions. Each session is consisted of 10 contractions in 10 seconds each with 50 seconds rest. ${ }^{11,12}$

Taking into account the physical and physiological differences of electric current in low and medium frequency and the lack of studies, this research aimed to verify the effect of neuromuscular electrical stimulation of medium and low frequency in the generation of torque in quadriceps femoral muscle in healthy subjects.

\section{MATERIALS AND METHODS}

This is a cross-sectional randomized controlled blind study. Thirty healthy individuals of both sexes (12 male, 18 female) where selected, average age of 24.67 year (SD 3.70), weight $65.62 \mathrm{Kg}$ (SD 15.21) and height $1.69 \mathrm{~m}$ (SD 0.11). Potential participants were excluded if they presented muscular recent lesion, knee injury, sensory changes, neuromuscular disease, morbid obesity and pregnancy. The project was cleared by the Institution's Ethics Committee (CEP 2.178.833) and all patients signed an Informed Consent Form. The choice of dominant lower limb was randomized with sealed envelopes. Thus, 16 right lower limbs and 14 left were selected (53.3\% and $46.7 \%$, respectively). Before being submitted to isokinetic evaluation, the volunteers performed the following protocol: 10 minutes by bicycle without load for warming, quadriceps and hamstring stretching muscles with 3 repetitions series of 30 seconds each. All individuals where familiarized with the protocol test that consisted of 4 seconds of submaximal isometric contraction (50-75\%), 4 seconds of isometric contraction associated with electrical stimulation (medium and low frequency). The aim of this familiarization session was to minimize any misunderstanding with the test, especially in relation to contraction associated with electrical stimulation.

This study was conducted at Cohen Orthopedic Institute, Rehabilitation and Sports Medicine - São Paulo - Brazil. KLD (Endophasis R) and Compex were used for NMES with medium and low frequency, respectively. We used two self-adhesive electrodes with dimensions of $4.5 \mathrm{~cm}$ $X 9.3 \mathrm{~cm}$. The evaluation of muscle strength was performed using the isokinetic dynamometer REV 9000 Technogym, Gambettola - Italy. The patient was placed in a sitting position, hip at $90^{\circ}$ flexion, knee at $60^{\circ}$ of flexion. The upper body was supported by the backrest with 2 crossed belts to stabilize the trunk and one pelvic belt. Final adjustments were made by alignment of the dynamometer rotating axis with knee joint axis. The resistance of lever arm was placed in the distal leg above the malleolus (Figure 1).

Individuals were submitted to the following 3 randomized test conditions:

- Four maximal voluntary isometric contractions (MVIC) of the femoral quadriceps muscle: 4 seconds each.

- Four MIVC of femoral quadriceps muscle (4 seconds each), associated with low frequency electrical stimulation (MIVC-LF). $75 \mathrm{~Hz}$ frequency, $400 \mu$ s pulse width; time on $=4 \mathrm{~s}$; time off $10 \mathrm{~s}$.

- Four MVIC of the femoral quadriceps muscle (4 seconds each), associated with medium frequency electrical stimulation (MVIC-MF), with the following characteristics: 75 burst $2500 \mathrm{~Hz} / \mathrm{s}$; time on $=4 \mathrm{~s}$; time off $=10$ seconds.

Current intensity modulation took into account the maximum tolerance of the patient without any pain. Cathode electrodes were placed on the vastus medialis muscle and the anode in the rectus femoris muscle (Figure 2).

The time between different conditions of isometric contractions was 90 seconds for adequate replacement of ATP ${ }^{13}$ and the time between isometric contractions in same conditions was 10 seconds. Randomized contractions sequence was applied with sealed envelopes and the volunteers were not aware by which electrical stimulation was being used. The examiner knew about the study because it required practice and knowledge with electrical stimulator.

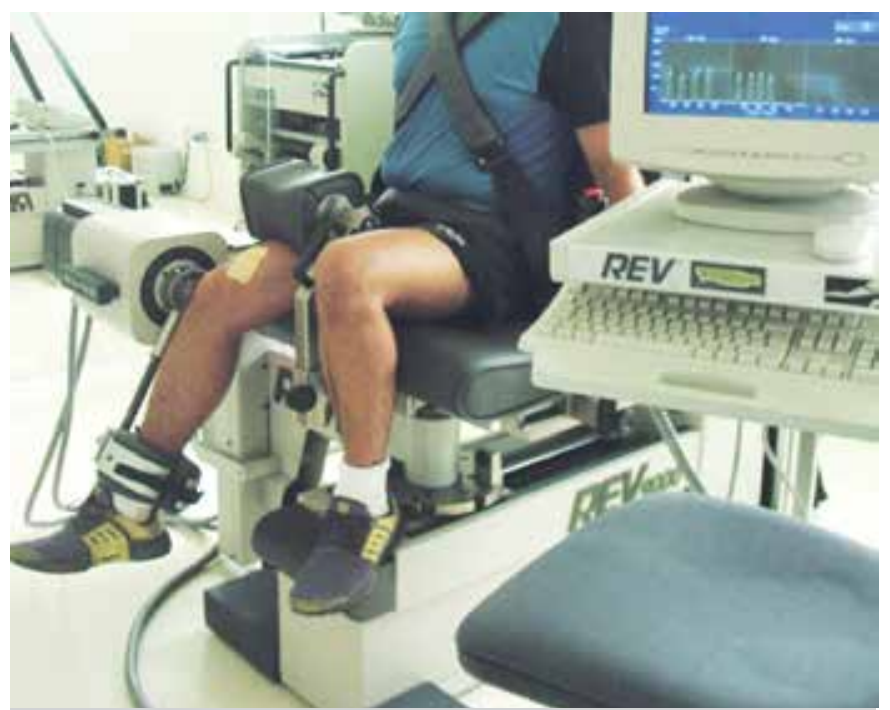

Figure 1. The patient is positioning in the isokinetic dynamometer with $60^{\circ}$ of knee flexion to evaluate isometric torque of femoral quadriceps. 


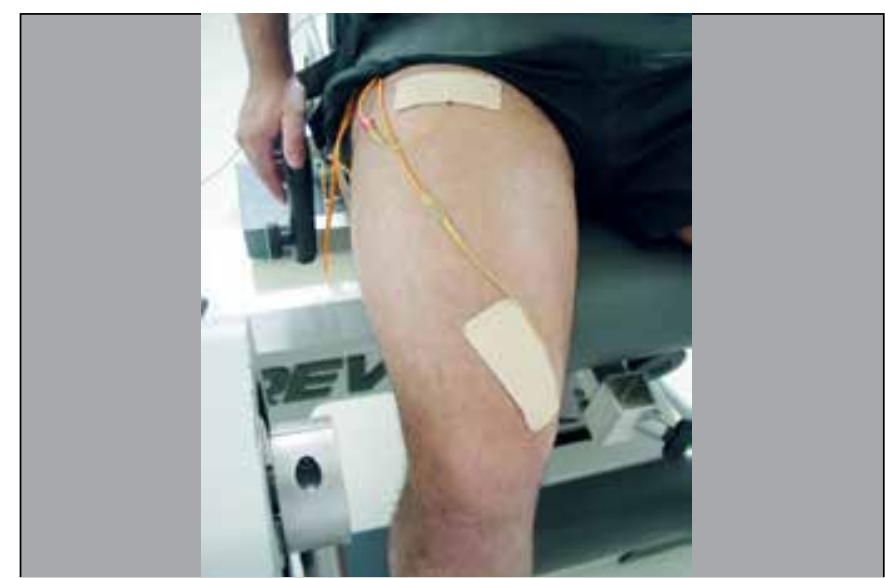

Figure 2. Placement of electrodes for neuromuscular electrical stimulation. Cathode in the vastus medialis muscle and anode in the rectus femoris muscle.

\section{RESULTS}

The measures of the variables of interest (MVIC) were obtained from the same person in three evaluations. This fact highlights the association between data collected in different frequencies. In view of this, to study the behavior of the MVIC variable in each situation considered, we apply analysis of variance (ANOVA).

It was found that there is difference between three measurements performed (Table 1). Statistically significant difference was found when compared MVIC-MF measures with MVIC-LF $(p=0.02)$ measures. When compare MVIC-MF with MVIC, the values for the average frequency was higher $(p=0.03)$, resulting statistically significant difference. Finally, comparing MVIC-LF with MVIC, there were no statistically significant difference $(p=0.52)$.

\section{DISCUSSION}

The use of NMES to gain muscle strength or performance in high-level athletes has been employed with frequencies by physiotherapists who work in sports. It was found that the medium frequency current is more comfortable and is able to generate a peak torque significantly higher than the low-frequency current.

Our findings may be based on the explanation that the higher the frequency, the lower the impedance to current flow and therefore more comfortable perception thereof. Thus, a larger current magnitude is permitted using the medium frequency current.

Another hypothesis for the increasing of peak torque with the medium frequency current is that current has been generated by a clinical device, as portable devices (battery) are not displayed when the goal is the strength of recovery femoral quadriceps muscle in patients undergoing reconstruction of the anterior cruciate ligament. ${ }^{14}$

Difficulties were found when comparing the results of this study to another works in literature because of differences in isokinetic evaluation protocols. In this study we choose the angle $60^{\circ}$ of knee flexion, because in this angulation the isometric muscle contraction reaches its maximum peak torque.

The sequence of NMES application was randomized to minimize the bias of muscle fatigue when generated by the medium current, low frequency or MVIC.

The electrodes positioning was based on the direction of quadriceps muscle fibers, with the focus on the rectus femoral and vastus medialis oblique. The placement of the electrodes can interfere with the extensor torque of the quadriceps muscle and that this type of placement is effective in producing a significant peak torque. ${ }^{15}$ Moreover, this parameter must be considered when using electrical stimulation or during interpretation studies.

The fact of the medium frequency current generate a peak torque average greater than the low frequency does not necessarily imply its effectiveness when introduced into a strengthening muscular program. In other study evaluated the isokinetic strength of the quadriceps muscle in healthy subjects after 3 weeks of training with medium and low-frequency current, finding a significant increase after training in both groups, but there was no difference between them. ${ }^{16}$ However, medium frequency current can lead to increasing muscle fatigue when compared with the low frequency current. ${ }^{17}$

This study was conducted in healthy and young adults. Thus, we cannot extrapolate our results to individuals who have a muscular deficit due to some involvement of the lower limb, as well as in patients undergoing knee surgery. A systematic review ${ }^{18}$ concluded that in healthy volunteers, exercises can be equally or more effective than electrical stimulation and the realization of an associated contraction appears to be relevant to the effectiveness of neuromuscular electrical stimulation. However, reports that more research is needed to quantify and establish the optimal parameters of electric current.

Authors investigated muscle biopsy before and immediately after medium frequency electrical stimulation $(2500 \mathrm{~Hz}, 50 \mathrm{~Hz}$ to $80 \%$ of maximum isometric torque). ${ }^{1}$ A decrease in glycogen of type II fibers was found, which according to the authors support the use of medium frequency electrical stimulation as a viable technique to be used in patients with impairment of type II fibers.

In the other study, author reports that electrical stimulation of $2500 \mathrm{~Hz}$ was applied to the triceps and biceps, with a 10-second contraction time and standby time of 50 seconds. ${ }^{12}$ This study evaluated strength, endurance, perimetry and fat percentage. These findings suggest that electrical stimulation alone is not an appropriate form of strength training in healthy subjects. In addition, to gain strength voluntary exercise should be worked with.

In other study, authors evaluated that electrical stimulation $(2500 \mathrm{~Hz})$ is able to increase strength compared to an isometric exercise protocol. ${ }^{19}$ After 25 sessions, there was no significant difference in increasing strength in the group of isometric exercises and the group stimulated electrically.

Although the present study did not have done any training to gain muscle strength, it may be suggested that the electrical stimulation with medium frequency promotes higher muscle fiber recruitment to gain muscle strength, because of the significant peak torque measurements increase. Although the present study did not have done any training to gain muscle strength, it may be suggested that the electrical stimulation with medium frequency promotes higher muscle fiber recruitment to gain muscle strength, because of the significant peak torque measurements increase.

\section{CONCLUSION}

Individuals when submitted to MVIC-MF showed higher peak torque than when subjected to MVIC-BF and MVIC alone. Thus it can be concluded that maximal voluntary isometric contraction associated with medium frequency NMES was more effectiveness than other situations of MVIC.

AUTHORS' CONTRIBUTIONS: Each author made significant individual contributions to this manuscript. CEP (0000-0002-6111-7195) ${ }^{\star}$, RACA (0000-00023849-0872)*, LMI (0000-0001-6710-1998)* and RPP (0000-0002-5934-2991)* were the main contributors to the writing of the manuscript. CEP and RPP performed the data collections, monitored the subjects and gathered the clinical data. RACA and LMI performed the statistical data analysis. CEP, RACA, LMI and RPP reviewed the manuscript and contributed to the intellectual concept of the study. ${ }^{*}$ ORCID (Open Researcher and Contributor ID). 


\section{REFERENCES}

1. Sinacore DR, Delitto A, King DS, Rose SJ. Type II fiber activation with electrical stimulation: a preliminary report. Phys Ther. 1990;70(7):416-22.

2. Kots JM, Hvilon VA. The training of muscular power by method of electrical stimulation. 1st ed. Moscú: State Central Institute of Physical Culture, 1971.

3. Maffiuletti NA, Zory R, Miotti D, Pellegrino MA, Jubeau M, Bottinelli R. Neuromuscular adaptations to electrostimulation resistance training. Am J Phys Med Rehabil. 2006;85(2):167-75.

4. Robinson AJ, Snder-Mackler L. Clinical electrophysiology: electrotherapy and electrophysiologic testing. 2 ed. Baltimore: Williams \& Wilkins Press, 1995.

5. Brasileiro JS, Villar AFS. Comparação dos torques gerados por estimulação elétrica a contração muscular voluntária no músculo. Rev Bras Fisio. 2000;4(2):75-81.

6. Robinson AJ, Snyder-Mackler L. Clinical Electrophysiology: Electrotherapy and Electrophysiologic Testing. 2ª ed. Baltimore: Williams \& Wilkins Press, 1995.

7. Ward AR, Robertson VJ, Makowski RJ. Optimal frequencies for electric stimulation using medium-frequency alternating current. Arch Phys Med Rehabil. 2002;83(7):1024-7.

8. Lyons GM, Leane GE, Clarke-Moloney M, O'Brien JV, Grace PA. An investigation of the effect of electrode size and electrode location on comfort during stimulation of the gastrocnemius muscles. Med Eng Phys. 2004;26(10):873-8.

9. Delitto A, Rose SJ. Comparative confort of three waveforms used in electrically eliciting quadriceps femoris muscle contractions. Phys Ther. 1986;66(11):1704-7.

10. Kots YM. Electrostimulation. (Canadian-Soviet exchange symposium on electrostimulation of skeletal muscles, Concordia University, Montreal, Quebec, Canada; December 6-15,1977). Quoted in: Kramer J, Mendryk SW. Electrical stimulation as a strength improvement technique. J Orthop Sports Phys Ther. 1982; 4:91-98.

11. Ward AR, Shkuratova N. Russian electrical stimulation: the early experiments. Phys Ther. 2002;82(10):1019-30.

12. Rich NC. Strength training via high frequency electrical stimulation. J Sports Med Phys Fitness. 1992;32(1):19-25.

13. Fleck S. Interval training: physiological basis. J Strength Cond Res. 1983;5(5):40-57.

14. Snyder-Mackler L, De Luca PF, Williams PR, Eastlack ME, Bartolozzi AR. Reflex inhibition of the quadriceps femoris muscle after injury or reconstruction of the anterior cruciate ligament. J Bone Joint Surg Am. 1994;76(4):555-60.

15. Hartssell HD, Kramer JF. A comparison of the effects of electrode placement muscle tension, and isometric torque of the knee extensors. J Orthop Sports Phys Ther. 1992;15(4):168-74.

16. Bircan C, Senocak O, Peker O, Kaya A, Tamci SA, Gulbahar S, et al. Efficacy of two forms of electrical stimulation in increasing quadriceps strength: a randomized controlled trial. Clin Rehabil. 2002;16(2):194-9.

17. Laufer Y. Ries JD, Leininger PM, Alon G. Quadriceps femoris muscle torque and fatigue generated by neuromuscular electrical stimulation with three different waveforms. Phys Ther. 2001;81(7):1307-16.

18. Bax L, Staes F, Verhagen A. Does Neuromuscular Electrical Stimulation Strenghten the Quadriceps Femoris? A systematic review of randomized controlled trials. Sports Med. 2005;35(3):191-212.

19. Laughman RK, Youdas JW, Garrett TR, Chao EY. Strength changes in the normal quadriceps femoris muscle as a result of electrical stimulation. Phys Ther. 1983;63(4):494-9. 